\title{
La educación media como espacio de disputa La deconstrucción del discurso sobre la sexualidad en Costa Rica, 1960-2018
}

High school education as a space of struggle

Deconstructing the discourse on sexuality in Costa

Rica, 1960-2018

O ensino secundário como um espaço de disputa A desconstrução do discurso sobre a sexualidade na Costa Rica, 1960-2018

Hermes Campos-Monge Estudiante. Escuela de Historia Universidad Nacional Costa Rica

Recibido: 20/08/2020 - Aceptado: 12/11/2020

\section{Resumen}

En 1985 se elaboraron textos denominados guías sexuales, cuyo fin era brindar un material de apoyo para el desarrollo de las lecciones de afectividad y sexualidad en las escuelas secundarias de Costa Rica. Desde entonces, una fuerte oposición a un material nuevo, más científico e inclusivo despertó una polémica de años entre grupos conservadores y religiosos y la necesidad de brindar un programa de formación a las juventudes que fuera más real. Este artículo plantea que los programas de educación

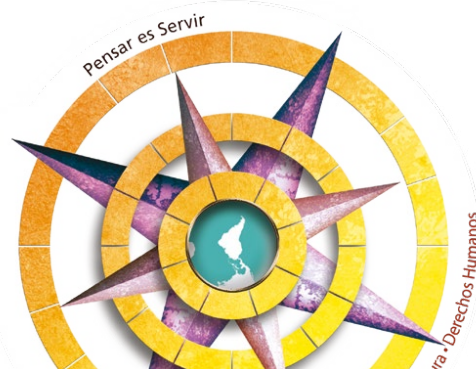
para la sexualidad han sido objeto constante de críticas y discusiones de origen ideológico, que han llevado a la educación media costarricense a convertirse en un espacio de disputa; donde la representación adultocentrista ha atravesado el discurso sobre 
sexualidad/sexualidades y ha dejado de lado la opinión del sector más importante: el estudiantado adolescente.

Palabras clave: Sexualidad, corporalidad, poder, discurso, programas educativos, Costa Rica, Temas de Nuestra América.

Abstract

In 1985, so-called sexual guides texts were developed to provide support material for the development of lessons on affectivity and sexuality in Costa Rican high schools. Since then, fierce opposition to a new, more scientific and inclusive material sparked a years-long controversy between conservative and religious groups and the need to provide a more realistic education for youth. This article argues that the sex education programs have been the subject of constant criticism and discussions of ideological origin, which has led Costa Rican secondary education to become a space of dispute; where the adult-centered representation has crossed the discourse on sexuality/sexualities and has left aside the opinion of the most important segment: the teenage student

Keywords: Sexuality, corporeality, power, discourse, educational programs, Costa Rica, Temas de Nuestra América, Costa Rica

\section{Resumo}

Em 1985, foram desenvolvidos textos chamados guias sexuais para fornecer material de apoio ao desenvolvimento de lições sobre afectividade e sexualidade nas escolas secundárias da Costa Rica. Desde então, uma forte oposição a material novo, mais científico e inclusivo provocou uma controvérsia de anos entre grupos conservadores e religiosos e a necessidade de proporcionar um programa de formação mais realista para a juventude. Este artigo argumenta que os programas de educação sexual têm sido objecto constante de críticas e discussões de origem ideológica, o que levou o ensino secundário costarriquenho a tornar-se um espaço de disputa; onde a representação centrada nos adultos cruzou o discurso sobre sexualidade/ sexualidades e deixou de lado a opinião do sector mais importante: os estudantes adolescentes.

Palavras chave: Sexualidade, corporeidade, poder, discurso, programas educativos, Costa Rica, Temas de Nuestra América 


\section{Las voces del discurso: Opi- niones de protagonistas en la deconstrucción sobre la se- xualidad 1980-2012}

Los programas de educación para la sexualidad han sido objeto constante de críticas y discusiones de origen ideológico, que han llevado a la educación media costarricense a convertirse en un espacio de disputa; donde la representación adultocentrista ${ }^{1}$ ha revestido el discurso de la sexualidad y ha dejado de lado la opinión del sector más importante, el estudiantado adolescente, al no promover que su participación sea más oficial, que la de un alumnado satisfecho o insatisfecho.

En las primeras guías sobre sexualidad que inician en año 1985, las referencias sobre los autores e integrantes de las comisiones curriculares encargadas de su revisión son muy limitadas y escuetas. Dentro de las instituciones mencionadas

1 Según Dina Krauskopf se refiere a: “... prácticas sociales que sustentan la representación de los adultos como un modelo acabado al que se aspira para el cumplimiento de las tareas sociales y productivas". Es decir, no ha bastado con poner a la persona adulta en el centro del universo político, sino que también la práctica ha impulsado el desplazamiento -por incentivo de apatía- de la participación juvenil en la política costarricense. aparece la UNESCO (Organización de Naciones Unidas para la Ciencia y Cultura), el FNUAP (Fondo de las Naciones Unidas para Actividades de Población) y el Ministerio de Educación Pública como entidad oficial. Estos primeros borradores de las guías de sexualidad fueron de gran ayuda para analizar los discursos desde donde se habla sobre la sexualidad y los enfoques utilizados para entender su dimensión humana. A mitad de la década de los 80 , a la sexualidad se le atribuye una perspectiva humana, al reconocer su dimensión emocional, cultural, moral, afectiva y psicológica, pero con la idea de que solo existen dos géneros:

La sexualidad humana es una dimensión de la vida que se ha desarrollado a partir del hecho de pertenecer a un sexo u al otro, condición que hace posible que las personas se vean a sí mismas y vean al mundo como hombres o como mujeres, con todos sus sentimientos, emociones, valores, expectativas, relaciones y actitudes. (MEP, 1985, p. 24)

Esta definición de una sexualidad centrada en la heterosexualidad ha sido por larga data objeto de luchas

2 Actualmente es lo que se conoce como Fondo de Población de las Naciones Unidas. 
feministas y abordado ampliamente en la bibliografía. En Costa Rica, Jacobo Schifter y la Fundación CEFEMINA $^{3}$ han generado aportes muy necesarios en la lucha contra el discurso hegemónico, cuestionando fuertemente al sistema patriarcal, criticando enérgicamente la naturalización de las categorías de hombre, mujer y sexo entre otros, amparados por el feminismo de la Segunda Ola como de la Tercera Ola. Entre los trabajos de Schifter se destaca $L a$ formación de una contracultura: Homosexualismo y SIDA en Costa Rica (1989), Las gavetas sexuales del costarricense y el riesgo de infección con el VIH (2002), han contribuido a desmantelar la normalidad y normatividad de los discursos sobre sexualidad, específicamente $L a$ formación de una contracultura, la primer obra escrita sobre la homosexualidad y SIDA en Costa Rica que, entre sus fuertes críticas, denuncia una ausencia de información, discusión y además, intimidación para quienes investiguen temáticas relacionadas con poblaciones disidentes,

3 Es el Centro Feminista de Información y Acción (CEFEMINA), trabaja en la defensa y promoción de los derechos de las mujeres. Sus objetivos están orientados a lograr el desarro1lo humano, lucha por la calidad de vida, los derechos de las mujeres y la erradicación de toda forma de discriminación de las mujeres, las adolescentes y las niñas. Tomado de https://www.cefemina.com/Nueva/ como los estudios gay en la Costa Rica de los años noventa (Schifter Sikora, 1989, p. 27).

Esta perspectiva heterosexual en la educación es consecuencia de un modelo cultural centrado en prácticas, dominio en los comportamientos, en el cuerpo y la mediatización de la cultura, que impone el sistema sexo-género como las dos únicas opciones. Al respecto Wittig (2006) plantea:

La categoría de sexo es una categoría política que funda la sociedad en cuanto heterosexual. La categoría de sexo es la categoría que establece como "natural" la relación que está en la base de la sociedad (heterosexual), y a través de ella la mitad de la población (mujeres) es heterosexualizada y sometida a una economía heterosexual. (p. 26)

De acuerdo con Wittig, el género tiene su cimiento en la categoría de sexo, porque no es solamente biológica o fisiológica, sino que es política pues construye el pensamiento, los gestos, los actos, el trabajo, las sensaciones y las relaciones. Por esta razón, la educación se vuelve un mecanismo de vital importancia como un medio de deconstrucción del aprendizaje, un artilugio que puede generar incomodidades

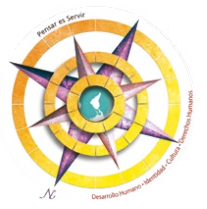


para quienes, desde posiciones de poder y privilegios, no desean ver interpelados y amenazados el orden tradicional.

Para 1989 la UNESCO y el MEP retoman la iniciativa de tratar de establecer un programa sobre sexualidad en el marco del proyecto: "Incorporación de Materiales de Educación en Población en el Tercer Ciclo de la Educación General Básica y en la Educación Diversificada del Sistema Escolar Formal" (aunque solo se realizaron las guías de tercer ciclo), (MEP, 1989). Este programa que trata de implementarse en Costa Rica tuvo un componente de sexualidad donde se abordaba anticoncepción, un poquito de infecciones de transmisión sexual (Cartín, 2019), por lo cual, se puede inferir que se trabajaba un enfoque de sexualidad basado en la prevención. No obstante, no ha sido posible establecer la definición incorporada sobre sexualidad en las guías, porque la unidad específica se extravió y solo se recuperó parte de la guía.

Respecto a la participación de sectores sociales en temas de relevancia nacional, no hay suficientes referencias para analizar posibles sesgos ideológicos y de contenido en las guías. No obstante, considerando algunos aspectos propios del género se puede determinar que la participación de las mujeres en la construcción de programas sobre sexualidad es limitada, y su lugar está fuera de puestos directivos y de coordinación, como se muestra en el siguiente cuadro:

Cuadro 1. Participación de mujeres y hombres autores en las guías de sexualidad 1985 y 1989

\begin{tabular}{|c|c|c|c|}
\hline $\begin{array}{c}\text { Guía didáctica de sexualidad y } \\
\text { vida familiar } \mathbf{1 9 8 5}\end{array}$ & \multicolumn{2}{c|}{$\begin{array}{c}\text { Guía didáctica de sexualidad y } \\
\text { vida familiar 1989 }\end{array}$} \\
\hline Mujeres & Hombres & Mujeres & Hombres* \\
\hline No hay datos & No hay datos & 3 & 4 \\
\hline
\end{tabular}

*De los cuatro hombres, dos de ellos tienen puesto directivo y de coordinación.

Fuente: Elaboración propia a partir de información disponible en las guías didácticas de educación en población de 1985 y 1989. 
No obstante, como no se indica quienes conformaron la comisión curricular, las posibilidades de analizar la tendencia discursiva desde el lugar del que se habla es limitada, porque se desconoce el área del conocimiento a la que pertenece y quiénes participan desde la sociedad civil. Por otra parte, durante la búsqueda de opiniones de sectores sociales en la prensa nacional escrita como periódicos, no se encontró mayor acervo documental que hiciera referencia a las Guías Didácticas de Sexualidad y Vida Familiar 1985 y 1989. Cabe resaltar, que la ausencia de reacciones en la prensa se debe a que estas primeras versiones fueron experimentales (MEP, 1989, p. 1) y parece, según la información, que no hubo conocimiento sobre las guías, pues el impacto mayor inicia a finales de la década de los noventa.

Iniciando la década de los noventa, oficialmente se crea una comisión curricular para elaborar la "Guía de Didáctica de Educación en Población 1990, en la que además de participar el Ministerio de Educación y la UNESCO, se suma un actor importante: La Conferencia Episcopal de Costa Rica" (Valerio Charpentier y Peralta Villalobos, 1990), (en adelante CECOR). No obstante, el documento no es claro en relación con los términos en los que ingresó la CECOR, pues al ser un documento del Estado debe garantizarse no solo la democracia (participación de distintos sectores sociales sobre un asunto de interés país), sino que debe procurarse por no revestir los programas con ideologías que puedan generar "daños colaterales, es decir, que quienes deciden qué se dice, no solos los mismos que sufrirán sus consecuencias" (Bauman, 2011, p. 13). Es decir, quienes implementan los programas, no necesariamente son los mismos que enfrentan las consecuencias de las políticas regulatorias de la identidad y la sexualidad, porque están dentro del poder político hegemónico. Además, este programa mantiene la misma definición de sexualidad de 1985.

Los obispos de la CECOR que participaron en la revisión de los contenidos mediante una comisión creada por ellos mismos reconocen públicamente que el trabajo que han constatado del MEP sobre las guías, es novedoso y lo defienden, ya que hay acusaciones de sectores (que no menciona) que intentan sabotearlo porque, según el Eco Católico (1992), se filtraron unos folletos sobre sexualidad no oficiales y se catalogaron de propagar el amor libre:

Ya las Guías (el problema es bien complejo) habían sido atacadas

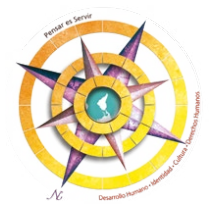


en forma exagerada por algunos y hasta difamadas por quienes ni siquiera las conocían. Muchos incluso recibieron folletos de "instrucción sexual" que confundieron con las Guías del MEP y por supuesto, muchos las declararon indecentes, inmorales $\mathrm{y}$ hasta de ser propaganda del amor libre. Yo creo que, hasta habrá quienes quisieran que no hubiese información ni formación sexual en las escuelas y colegios. Todo esto es parte de esa confabulación en contra de lo necesario para el bien. (p. 2)

No obstante, en 1993 se vuelve a plantear una nueva versión de los guías, con una leyenda que dice: "Segunda edición: incluye modificaciones resultantes de la introducción de elementos de la propuesta que la Conferencia Episcopal de Costa Rica entregó al Ministerio de Educación Pública en 1992" (MEP, 1993, p. 5), (situación que continuo hasta finales de los noventa). Esto sugiere que existió una constante inconformidad política e ideológica que se escapó de los intereses comunes entre la CECOR y el MEP. Esto es una suposición, ya que entre 19901992 no se encontró alguna noticia o documento que justificara con profundidad este argumento.
"No obstante, dos años después un jerarca de la Iglesia Católica emite un comunicado al Ministro de Educación, donde se solicita que las correcciones realizadas por ellos sobre las guías sexuales sean las que publiquen oficialmente" (Eco Católico, 1992). Esto parece indicar que efectivamente hubo un replanteamiento de los contenidos de las guías, lo cual puede responder a desavenencias sobre algún interés común que se vio afectado en la versión anterior. Es necesario recordar que las nociones de sexualidad, que tradicionalmente revisten sobre esta institución, responden a moralismos y prácticas propias de su fe, pero descontextualizadas de las necesidades y realidades de la sociedad adolescente.

Las Guías Didácticas del Área de Sexualidad Humana del Proyecto de Educación en Población de enseñanza media de 1990 y 1992 fueron revisadas por una comisión mixta designada por el ministro de Educación Marvin Araya Herrera y por delegados de la Conferencia Episcopal de Costa Rica. No obstante, la comisión de 1992 estuvo conformada por sacerdotes y laicos católicos nombrados por la CECOR (Valerio Charpentier y Peralta Villalobos 1993). La construcción de las guías, de acuerdo con la investigación, "tuvo mayor mediación por la 
jerarquía de la Iglesia Católica y el Opus Dei" (Cartín, 2019); no solo porque este sector representó mayor presencia en las comisiones de revisión, sino porque figuraba un poder político muy importante que podría generar un alto costo político al crispar en una posible contienda ideológica.

La crisis sobre las guías de la sexualidad que había iniciado con la primera publicación a inicios de los noventa conllevó a varios replanteamientos relacionados con el contenido y sobre las representaciones corporales en las imágenes:

Algunos cuestionamientos apuntaban a las ilustraciones dedicadas al cuerpo humano, así como información que se les suministraba al estudiantado acerca de los métodos anticonceptivos. Este tipo de situaciones generó en la sociedad dudas, inquietudes y desinformación de la comunidad costarricense. (Cartín, 2019)

El resquemor de la jerarquía de la Iglesia Católica, por la forma en la que se planteaban los contenidos en las Guías de Sexualidad, llevaron a un rompimiento de relaciones de diálogo mediante la suspensión de su representante de educación religiosa y la decisión de la CECOR de no otorgar validez a la información producida. A partir de ese momento, hasta finales de los noventa no se publica más materiales sobre sexualidad por parte del MEP (Cartín, 2019). No obstante, a finales de los noventa se edita un documento llamado "Manual Didáctico de Sexualidad Humana $8^{\circ}$ Tercer Ciclo, 1999" que, aunque no fue publicado, posee un discurso necesario de analizar en el marco de las presiones que tenía en la mira a la educación sobre la sexualidad. Este texto debía ser sometido a revisión, pero no hubo mayor cambio, debido a que el gobierno Rodríguez Echeverría (19982002), a través del Despacho de la Primera Dama, asume esta labor:

...dirigido a profesores de enseñanza media, con el fin de "teorizar sobre sexualidad" humana, donde se reconoce la vida desde la concepción, la familia como institución legitima para enseñar sobre sexualidad, la adolescencia como un problema (crisis de identidad), aceptación incuestionable del cuerpo, preparación para el noviazgo y el matrimonio entre otros. Además, es importante mencionar que el documento también reconoce el embarazo no deseado, el aborto, las enfermedades de transmisión sexual y el SIDA como una consecuencia del mal manejo de la sexualidad. (MEP, 1999, pp. 4-13) 
La llegada del Gobierno Rodríguez Echeverría (con un rol claramente asistencialista), retorna la crispación social sobre quienes tienen la verdad sobre qué y cómo se debe de enseñar la sexualidad en Costa Rica. En 1999 se aprueba el proyecto: Amor Joven y Construyendo Oportunidades, auspiciado por el Despacho de la Primera Dama y el Consejo Interinstitucional de Atención a la Madre Adolescente, que planteaba que la sexualidad, además de ser inherente a la vida humana, no está determinada exclusivamente por factores biológicos, órganos, genitales o la capacidad de dar vida. Según el documento:

...la sexualidad tiene que ver con muchas otras cosas, con nuestros sentimientos, nuestras emociones, con las relaciones que establecemos con otras personas, con las posibilidades de satisfacer nuestras necesidades, con ser feliz, sentir placer y cariño, protegerse, sentirse bien con una/o mismo, ósea, tiene que ver con nuestra existencia. (Oficina de la Primera Dama y Consejo Interinstitucional de Atención a la Madre Adolescente, 1999, p. 6)

Esta perspectiva de la sexualidad generó anticuerpos en sectores sociales como la jerarquía de la Iglesia Católica, quienes desacreditaban el trabajo de la primera dama al calificarlo como una estrategia para minimizar el papel de la familia en la sociedad costarricense:

Monseñor Héctor Morera dijo "estos proyectos auspiciados por la Oficina de Primera Dama tienen a minimizar los papeles de la familia y de los padres para con sus hijos. Tienden a buscar el libertinaje de jóvenes, desorientados y estimular las conductas homosexuales y el lesbianismo". (Mora, 1999, p. 16A)

No obstante, estas posiciones también pueden ser consecuencia de discursos míticos que se equiparan a una forma atenuada de conocimiento $\mathrm{y}$, de algún modo, de cierto control social, en la medida en que los mitos acerca de la sexualidad continúen privando como elementos de orden cultural y natural. Según Gatjens (2006):

...Para comprender por qué el mito entra necesariamente en la vida humana, basta considerar lo limitado de la información que nos brindan sobre nuestros cuerpos (impulsos, satisfacciones y frustraciones). Una segunda acepción, que podemos llamar sociológica, entiende que el mito equivale a una falsificación de la realidad motivada por intereses políticos, económicos u otros. 
Mito e ideología sería términos cercanos, los cuales designan un particular modo de control social. (p. 46)

No obstante, en octubre de 1999 jerarcas de la Iglesia Católica y el Gobierno logran una alianza con el fin de ajustar los contenidos del programa Amor Joven, y lograr una educación sexual con la consigna de una sexualidad plena y responsable, sin omitir la familia como eje fundamental de enseñanza. La preocupación de la Iglesia era que, en la sexualidad, el placer llegara a ocupar un espacio relevante, como se expresa en la siguiente nota:

El canciller de la Iglesia, Monseñor Antonio Troyo Calderón, comentó en esa ocasión que: "pareciera, y así lo sentimos, que hay un poco de peligro al querer dar a la educación sexual una línea de enfoque solo de placer. Los educadores no pueden dejar de lado el énfasis familiar, eje fundamental de esta enseñanza". (Chacón Román, 1999, p. 3)

Gran parte de las sociedades occidentales, advierte Van Dijk (1999), están dominadas principalmente por elites, es decir, "por aquellos que tienen los recursos sociales, que las personas ordinarias no poseen; ya que su acceso es marginal y esencialmente pasivo a ellos" (p. 33). Estos dispositivos de poder discursivo son el caldo de cultivo para mantener simbólicamente el lugar que deben ocupar las personas y las cosas; es decir, estas representaciones ampliamente compartidas por gran parte de la sociedad, agravan y redefinen la desigualdad social.

El Gobierno reconoce con satisfacción el consenso al que ha llegado con la jerarquía de la Iglesia Católica. No obstante, según una noticia publicada por La Prensa Libre, en el año 2000, la convocatoria para la elaboración de la segunda parte de los documentos del programa Amor Joven, donde participaría la CECOR nunca llegó y se iniciaron procesos de capacitación a docentes con materiales que contradecían el convenio:

La Conferencia Episcopal de Costa Rica, en su Asamblea Extraordinaria celebrada en pasado 14 de noviembre, analizó el Programa Amor Joven y Construyendo Oportunidades, en el que la Oficina de la Primera Dama de la República y la Iglesia han colaborado, mediante esfuerzos de una Comisión Mixta. En vista de que se ha constatado que en varios lugares se ha realizado entrenamiento a docentes, se distribuyen materiales que contradicen el documento convenido y cuyos contenidos no corresponden a la moral y antropología cristiana, se 
acordó por unanimidad no continuar con la colaboración Estado-Iglesia para la puesta en práctica del citado programa. (Vio Hernández, 2000, p. 12)

Esta noticia planea una interrogante muy interesante y está relacionado con la parcialidad del Estado para formular programas de educación sobre sexualidad libres de estigmas y mitos, y por otro lado, con las negociaciones revestidas de conveniencias políticas, donde es necesario sumar actores sociales para garantizar una "democracia" expresada en el diálogo y la consulta popular. Pero, en realidad, estos actores no son escuchados o bien su cosmovisión no corresponde con las formas de pensamiento del grupo élite. Esto de ninguna manera apela a clasificar lo bueno o malo, lo tradicional o lo liberal, sino que existen otros costos políticamente más altos (presión internacional) que el costo electoral que puede ocasionar del sector religioso en ese momento. Entonces, ¿cuáles son las condiciones sobre las que entro la Iglesia Católica? ¿Existía independencia ideológico-religiosa en el programa Amor Joven como inicialmente se planteó de acuerdo con los jerarcas de la Iglesia Católica? El apoyo de la jerarquía católica a los programas de "Amor Joven" y "Construyendo
Oportunidades", evidencia que sus condiciones como actor social fueron diferenciadas, al asumir un rol donde sus aportes debían considerarse como una visión oficial. Sin embargo, las autoridades del MEP negaron que existiera una participación en términos que no fueran los de un actor social:

En Amor Joven la participación de la iglesia fue ninguna, ese fue parte del problema de que se cayó. Porque hubo tanta presión del Opus Dei, -porque antes para las famosas guías de sexualidad de los 90,91-; era el MEP y la Iglesia Católica, que aun así fue la Iglesia Católica la que lo quitó. Pero en el proyecto Amor Joven, la participación de la Iglesia es nula; porque el Fondo de Población, el INAMU y el MEP se posicionan en el enfoque de derechos, entonces decimos: -metemos a la Iglesia Católica, tenemos que meter a todas las Iglesias-. Inclusive se hizo algún tipo de consulta como diciendo: esto es lo que se va a presentar, pero ustedes no van a determinar nada. (comunicación personal, Cartín, 2019)

No obstante, la Oficina de la Primera Dama continuó el proyecto que había iniciado, a pesar de las críticas de jerarcas de la Iglesia Católica. Ella estaba convencida sobre la necesidad de hablar sobre sexualidad a 
los jóvenes, no solo desde las aulas, sino la posibilidad de abrir espacios donde el adolescente y los adultos pudieran interactuar sobre temáticas asociadas a la sexualidad y sensibilizar la población sobre la responsabilidad de orientar a los jóvenes en esta materia, como se narra en su discurso:

...El objetivo de la campaña es crear conciencia acerca de la importancia de brindar información, orientación y educación de la sexualidad, mediante la conversación directa y clara entre los adolescentes y adultos. A partir del 1 de setiembre se iniciará la campaña que incluye dos cortos en televisión y tres cuñas de radio con el lema "Hablemos claro". (Sáenz Valverde, 2000,p. 6)

Por otra parte, la CECOR también publica unas guías sobre sexualidad dirigidas a padres de familia y educadores. Este documento está construido según los acuerdos aprobados entre el MEP y la Conferencia Episcopal y se titula: Educación en la Sexualidad: Guía para Padres de Familia y Educadores:

La guía incluye la segunda propuesta de los programas Amor Joven y Construyendo Oportunidades, aprobado por los obispos costarricenses. Sin embargo, el folleto excluye las modificaciones hechas por el gobierno de Costa Rica por las cuales la Iglesia Católica retiro su consentimiento. (Castillo, 2001, p. 10)

La guía de la CECOR plantea elementos muy interesantes amparados en la legislación costarricense, con el fin de justificar y legitimar el contenido. Sus planteamientos están amparados en la Constitución Política, el Código Civil, el Código de Familia y jurisprudencia de la Sala Constitucional (que no se detallará en este artículo) en relación con algunos temas que han sido cuestionados por la Conferencia Episcopal en las guías sobre sexualidad desarrolladas por el MEP, como por la Oficina de la Primera Dama Lorena Clare; esta última fue la que propició la creación de este documento. Los tópicos abordados "son: la vida humana inviolable, la familia como elemento natural y fundamental de la sociedad, el matrimonio heterosexual como base esencial de la familia" (Conferencia Episcopal de Costa Rica, 2001, pp. 9-16). No obstante, la CECOR parece omitir un principio elemental del derecho: el derecho es progresivo e irreversible. Por eso, los programas sobre sexualidad deben responden a un marco jurídico nacional como internacional, como se expresa el artículo 7 de la Constitución Política y lo reitera

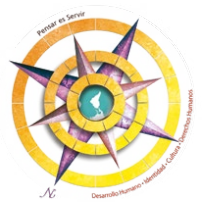


la jurisprudencia de la Sala Constitucional en la sentencia 16583-15:

En el caso de Costa Rica, por decisión del constituyente derivado en la reforma constitucional al artículo 7 en 1968, prevalecen los Tratados por encima de las normas ordinarias del sistema legal, lo que descarta toda discusión sobre la vigencia de esas normas con las leyes en el tiempo. Así, con base en la argumentación de los accionantes debe determinarse, cuáles son los derechos internacionalmente reconocidos por los sujetos de derecho internacional, que no se estarían aplicando directamente en el país, o no se estarían materializando en las normas nacionales, pese a que existe un compromiso libremente aceptado por el Estado costarricense. (Poder Judicial de Costa Rica)

Las argumentaciones de la CECOR son válidas en tanto están dentro del marco jurídico nacional, pero bajo ninguna circunstancia un derecho puede oprimir otro o generar exclusión. La educación para la sexualidad es un derecho reconocido en la Declaración de los Derechos Sexuales de 1997 y no se puede negar una educación integral y comprensiva de la sexualidad, sin negar ese derecho:

el derecho a una sexualidad sana, a la libertad y la protección contra toda forma de coerción sexual, explotación y abuso; el derecho a la autonomía, integralidad y seguridad del cuerpo, para tener el control y goce de los propios cuerpos, libre de torturas, mutilaciones y violencia de cualquier naturaleza, el derecho a la igualdad y equidad sexual, para ser libres de toda forma de discriminación, a través del respeto de la diversidad sexual, sin importar el sexo, género, edad, raza, clase social, religión y orientación sexual. (Arroyo Navarrete, 2008, p. 137).

El discurso sobre la sexualidad no es una narrativa construida desde los estamentos nacionales o desde perspectivas conservadoras o liberales de sectores sociales nacionales; involucra perspectivas jurídicas y de salud, entre otras. Hay participación de actores internacionales y decisiones asumidas por el país mediante la firma y ratificación de convenios internacionales, donde de forma voluntaria, el país se compromete al cumplimiento y garantía de estos. No obstante, estos actores han sido cuestionados por sectores sociales como la jerarquía de la Iglesia Católica y grupos evangélicos que se oponen a las políticas progresistas, aduciendo a un intervencionismo sobre la soberanía nacional, que se explicará con más detalle finalizando este apartado. 
En 2001 ocurre un acontecimiento político que dará validez para desarrollar una estrategia país para impulsar y ejecutar acciones ministeriales sobre la sexualidad; ya que anteriormente solo ejecutaban iniciativas mediante instituciones modelo ${ }^{4}$ en sectores con mayor vulnerabilidad en temas de embarazo adolescente, prevención del abuso sexual e infecciones de transmisión sexual, como lo expresa Cartín (comunicación personal, 2019):

En el 2001 se considera que es básico que tengamos una política interna de Educación Integral de la Sexualidad. Interna para MEP para poderle decir a todo el Ministerio y ya no a las Instituciones Modelo, sino a todo el Ministerio de Educación; la educación integral de la sexualidad en este Ministerio va a ser esta, esta y esta.

Esta política se aprobó el 12 de junio del 2001, en la sesión 28-2001 del Consejo Superior de Educación con el liderazgo de la primera dama Lorena Clare, con el fin de institucionalizar la educación para la sexualidad en el Ministerio de Educación Pública. De acuerdo con Cartín, esta política fue elaborada en consenso

4 Las instituciones modelo se refiere a lugares (centros educativos) donde se hacían pilotajes sobre temas vinculados a la sexualidad, de acuerdo con Tatiana Cartín, entrevista personal, realizada el 24/07/2019 con la jerarquía de la Iglesia Católica y con una fuerte incidencia política para lograr su aprobación. Este documento reconoce la definición de sexualidad acuñada por el Consenso del Vaticano II que establece:

La sexualidad humana es un bien: parte del don que Dios vio que "era muy bueno" cuando creó la persona humana a su imagen y semejanza, y "hombre y mujer los creó". En cuanto modalidad de relacionarse y abrirse a los otros, la sexualidad tiene como fin intrínseco el amor, más precisamente el amor como donación y acogida, como dar y recibir. (MEP, 2001, p. 1)

La parcialidad del Estado costarricense vuelve a estar en discusión, y la jerarquía de la Iglesia Católica parece estar en una condición diferenciada sobre otros grupos sociales que participan en procesos de revisión y consulta sobre los programas de sexualidad. No obstante, esta posición de privilegio puede ser consecuencia de "las relaciones cercanas que mantenía el Ministro de Educación Guillermo Vargas con el OPUS DEI" (Cartín, 2019). No obstante, esta acción del Estado puede mirarse desde dos ángulos: una está vinculada a la fragilidad político-electoral frente a sectores que tienen la capacidad de aglutinar y mover masas e inducir sobre en el costo electoral;

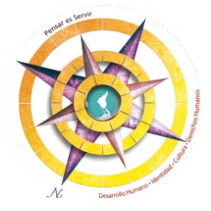


además también puede estar influenciado de un reconocimiento o logro político que distinga su gestión.

La política planteaba que era indispensable trabajar trasversalmente la sexualidad, eso implicaba que en todas las materias debería de analizarse el tema. Además de las reacciones antagónicas dentro de la sociedad, la acción de transversalizar estaba sujeta a la decisión del docente, porque no existía ningún mecanismo que garantizara el cumplimiento de esta política. Por esta razón era necesario iniciar un proceso de capacitación y sensibilización a docentes:

Entonces a nosotros como Departamento se nos da el encargo de capacitar por direcciones regionales y así lo hacemos. Hacemos un curso básico de 5 días sobre derechos humanos, alimentos básicos biológicos, afectivos y demás. Eso se iba a las regionales y todo el mundo en la regional: desde el profesor de cívica hasta el de matemática tenían que llevarlo para poder implementar eso en sus materias de manera transversal. (Cartín, 2019)

No obstante, en la expectativa social se percibe una ausencia de programas sobre educación para la sexualidad, e incluso existió un pronunciamiento por parte de la Defensoría de los Habitantes, donde aducía que, a pesar de la existencia de una política en MEP, no se había creado un programa para la sexualidad; mientras las cifras de nacimientos seguían aumentando y se convertía en un problema social grave, como se publicó en el periódico La Prensa Libre:

Encerrada en palabras tabú, la educación sexual continúa resolviéndose en los pasillos del cole y no en las aulas. Estudiantes y profesores están preocupados, pues el 20 por ciento de los nacimientos que se dan en el país es de jóvenes menores de 18 años, y el 6.7 por ciento de niñas menores de 15 años. (Zúñiga Ureña, 2003, p. 5)

Sin embargo, es necesario resaltar que la política tiene sus limitaciones al no promover la elaboración de planes curriculares con enfoques estructurados, ya que esta misma se había diseñado para abordarse desde la trasversalidad. De acuerdo con Cartín (2019), "la transversalidad entra ahí en un bache, pero aun así 2001, 2002, 2003 y 2004 se trabajó asî". Este escenario planteaba importantes retos para el MEP, no solo por la presión de la Defensoría de los Habitantes, "quien le solicita al MEP ahondar el tema de la educación sexual en los programas educativos, por las alarmantes cifras de adolescentes y niñas que esperan un hijo" (Zúñiga Ureña, 2003, p. 5); sino que 
debía enfrentar la lucha ideológica y política con jerarcas de la Conferencia Episcopal, quienes obsesionados con la producción textual, buscaban oportunidad para emitir documentos sobre este tema. ${ }^{5}$

Actores sociales como la jerarquía de la Iglesia Católica comenzaron a percibirse como una molestia, quizá por los diferentes escándalos y desacuerdos en materia de sexualidad, frente a un aumento escabroso de índices de natalidad (embarazo adolescente) que impactaban mayormente a mujeres entre 15 y 18 años. Una noticia publicada por La Prensa Libre, titulada "Iglesia no debe intervenir en educación sexual" plantea:

Después de tres días de intensa discusión, la Asociación Nacional de Profesores de Segunda Enseñanza (APSE) fijó su posición en torno a la educación sexual que se imparten en los colegios públicos, en la cual no debe participar la Iglesia, por ser tan poco realista. "Estamos de acuerdo que la educación debe ser integral y con un componente importante relacionado con los valores, tal y como lo promueven los líderes

5 Algunas de las publicaciones que emitió la CECOR durante el período 2001-2009 fue: Educación en la Sexualidad: Guía para Padres de Familia y Adolescentes 2001; Aprendiendo a Querer 2004 (diez tomos); Sexualidad Don y Responsabilidad 2005 y Amor y Sexualidad 2009 (seis tomos). religiosos del país; sin embargo, debemos tomar en cuenta el proceso de transculturalización que nuestros jóvenes toman de otros países como Estados Unidos". (Arrieta Arias, 2004, p. 7)

Sobre este panorama, con la insistencia de la CECOR, advierte Bauman (2011, p. \#): "las obsesiones por la seguridad son inagotables e insaciables: una vez que se desatan y levantan vuelo, no hay manera de detenerlas". El caldo de cultivo que se venía gestando en la sociedad costarricense, sobre la incertidumbre, miedo e inseguridad sobre lo que se iba a enseñar en las aulas, era suficiente para generar un caos social; caos que se acrecentaba sin una razón clara, pues todavía no existía un programa específico sobre sexualidad y de existir, posiblemente, la reacción seria la misma, dado que lo desconocido y enigmático genera cierto miedo y malestar, inconsciente o conscientemente en las personas a quienes se les ve amenazado su orden.

Desde la creación de la Política de Educación Integral de la Expresión de la Sexualidad Humana (2001) no se había logrado concretar un programa estructurado. Sin embargo, fue durante la segunda Administración de Leonardo Garnier (20102014) cuando se logra elaborar e

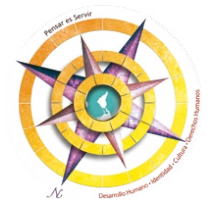


implementar el Programa de Educación para la Afectividad y Sexualidad Integral, que se incorporó en el programa de ciencias por la siguiente razón:

Por qué en ese momento era el que cubría el área de los estudiantes, la materia o la asignatura que cubría el área de los estudiantes que era como con más problemática, que se estaba presentando más embarazos, más violencia en esa etapa etárea, en ese grupo de estudiantes. Entonces fue ahí ¿Dónde en qué materia tenía que ser? ¿Dónde lo incorporábamos? Estaban los compañeros de orientación, pero ellos no cubrían todo el grupo de estudiantes del país. Entonces ciencias si tenía unas áreas muy afines, cómo cuando se daba el sistema reproductor, que aunque era muy temático, pero que era donde podía incorporarse esta área de afectividad y sexualidad, por eso ahí se pensó que tenía que entrar en Tercer Ciclo en Ciencias. (Sevilla y Campos, 2019, p.\#)

Aunque existen razones de índole técnico sobre la decisión de utilizar la asignatura de ciencias para incorporar el Programa de Afectividad y Sexualidad Integral (en adelante PASI), es insuficiente para abordar una temática de tan profunda complejidad, porque interpela las estructuras más íntimas y profundas de la sociedad y requiere un proceso de lectura, en donde el estudiante pueda, con ayuda del facilitador, deconstruir los paradigmas de la sexualidad y asumirlos desde su propia experiencia y conocimiento, para que estas enseñanzas puedan permear.

Sobre este documento se realizaron procesos de consulta a distintos grupos sociales como: religiosos, instituciones del Estado y organizaciones no gubernamentales. A diferencia de procesos anteriores, la participación de jerarcas de la Iglesia Católica estuvo equiparada en igualdad de condiciones respecto a los demás grupos.

Lograr elaborar e implementar un programa sobre sexualidad conlleva a preguntarse: ¿cómo logró Leonardo Garnier lo que anteriores ministros intentaron hacer sin éxito? Algunas de las interpretaciones sobre el logro de Garnier se han enfocado en que hubo un contexto en el escenario nacional e internacional que lo permitió. El primer elemento es la voluntad política, la apertura para desafiar los cimientos de una cultura altamente resistente a mirar realidades invisibilizadas. Además, se busca garantizar el derecho a una educación laica y replantear el concepto 
"tradicional" de familia, ya que no existe una familia tradicional en su sentido más estricto, sino que depende de la experiencia propia de cada sujeto lo que la define. Un segundo elemento puede ser el cambio generacional, es decir, probablemente las personas de mayor edad son quienes continúan manteniendo esquemas muy estrechos sobre la sexualidad, mientras que los jóvenes están expuestos a un mundo cosmopolita, donde la interacción con otras culturas puede transformar el marco referencial de las personas y confronta tanto la moralidad como los valores personales. Este escenario pudo ser un aliciente para las transformaciones gestadas en la educación costarricense sobre la sexualidad.

Efectivamente, el discurso de la sexualidad en Costa Rica no está limitado a la versión oficial, existen muchos lugares desde donde se habla y se deconstruye la narrativa de la sexualidad. Se puede definir como una narrativa en tanto exista participación de distintos actores y escenarios, pese a que la legitimidad oficial sobre la enseñanza de la sexualidad recae en el MEP, la existencia de otras voces no oficiales siempre estará en el escenario.

La educación media es una representación de las distintas narrativas, pues los sujetos no solo interactúan con el sistema educativo, también lo hacen con las construcciones simbólicas sobre la sexualidad en la sociedad, en los medios de comunicación, en las familias, en los lugares de recreación, centros de pensamiento, etc., lugares desde donde se generan transformaciones y resistencias para mantener el statu quo o para desafiar las normativas culturales y sociales sobre la sexualidad.

\section{Inspección sobre los cuerpos: La sexualidad y los medios de difusión sobre el discurso ofi- cial 2001-2018}

Cada sociedad, a razón de resguardar su narrativa, crea estrategias discursivas para proteger, reproducir o mantener un orden normativo y heteronormativo en relación al control de los cuerpos. Es decir, la sociedad se encuentra ante una nueva forma de gobierno, que basa sus políticas en el control de aspectos de la vida cotidiana y en la modalización de los comportamientos; es decir, "el ejercicio del poder sobre la vida, que buscará defender las poblaciones sanas y productivas de aquellos individuos que resulta menester resocializar o exterminar en nombre de la perdurabilidad de la especie, en palabras de Michael Foucault, el biopoder" (Díaz, 2013, p. 3). Esto significa que

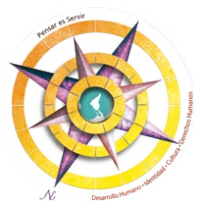


el cuerpo individual como colectivo se vuelve objeto y sujeto de interés de la clase gobernante, cuyo fin es curar el problema social (enfermedades físicas y morales) sobre el cuidado de los cuerpos, como se puede analizar en el siguiente texto:

La educación de la expresión de la sexualidad humana - como derecho y deber primero de la familia y subsidiario de la escuela - debe comenzar desde la primera infancia y prolongarse a lo largo de toda la vida, atendiendo educativamente en forma específica las necesidades y las características propias de cada período del desarrollo de la personalidad. (MEP, 2001, p. 5)

El Estado se vuelve un actor muy importante en tanto es una institución legítima para implementar políticas sobre cómo se entiende y debe abordar las temáticas sobre sexualidad, cuyos contenidos deben responder al orden hegemónico. Aunque en el proceso de formación y redacción del discurso participan otros actores sociales, las potestades de la institución legítima le permiten decidir cuáles voces de los actores involucrados se consideran y cuales son desechadas, cuando los criterios son o no compartidos dentro de los espacios de toma de decisión.
Los discursos oficiales desde instituciones legítimas, son legítimas en tanto la misma pueda generar confianza y concuerde con las visiones emanadas desde la sociedad. La narrativa de la sexualidad posee dos bandos mayoritariamente muy importantes y antagónicos: el MEP como entidad rectora y reconocida en materia de educación y la Iglesia Católica, como institución rectora del orden moral y cuyas políticas tienen mayor cercanía con una población que se opone a las transgresiones del orden natural. Desde este panorama, el MEP debe considerar cómo jugar con los discursos conservadores que pueden implicar costos electorales graves, o valorar si el beneficio obtenido políticamente motiva un desafío abierto, al implementar políticas y programas que no son avalados por sectores como la Iglesia; pues el discurso oficial siempre tendrá aliados y adversarios para tratar un mismo problema social, lo que conlleva a plantear vías y soluciones para dar respuesta a estos escenarios. Así lo reconoce Carlos Avendaño (2003) en una entrevista publicada por el Heraldo de la Nueva Era donde establece:

El tema de la educación sexual ha generado las más diversas polémicas en el pasado reciente de nuestro país. El debate ha tenido 
tintes de fundamentalismo religioso, sociológico, psicológico... en fin, las posiciones radicales habían permeado la discusión. Nosotros nos oponemos a los radicalismos contrastados, que no hace sino complicar más el problema. No se nos debe confundir. Es totalmente válido que cada quien asuma su posición con firmeza, como la nuestra, que es una posición cristiana inspirada exclusivamente en las Sagradas Escrituras. (p. 14)

De acuerdo con Foucault, las tecnologías de la normalización y las instancias disciplinarias logran su cometido gracias a las instituciones de encierro como la educación, cuyo fin es crear: sujetos homogéneos, normalizados, regularizados, evaluados, dóciles y obedientes; expuestos continuamente a diversos procedimientos de vigilancia, control y bajo permanente escrutinio (Sánchez Amaya, 2013, p. 756). Para Foucault, la tecnología es un dispositivo para la reproducción del poder, es institucionalizado y consciente, porque se elabora en función de algo que se quiere tener como resultado. Por ejemplo, los programas de sexualidad son un dispositivo consciente, que busca un resultado especifico, pero lo que se aprende no necesariamente es lo que va a reproducir.
Este escrutinio se lleva a cabo a través de programas y políticas sobre sexualidad que buscan administrar la vida de forma consciente, pero donde existe resistencia al dominio y a la subyugación, se apela a lo que establece Bauman (2011) "una vez despojado el otro de 'rostro' su debilidad invita a la violencia con naturalidad y sin esfuerzo" (p. 84). La resistencia a la obediencia lleva implícito el ejercicio de cualquier forma de violencia cultural, simbólica, estructural e incluso al exterminio como la máxima expresión de penalización.

"Las dinámicas del bio-poder emergen como políticas regulatorias que apuntan a la administración de la vida de ese nuevo sujeto colectivo que es la población" (Bottice1li, 2015, p. 86); estos controles se efectúan por medio de programas tendientes a la modalización de conductas definidas como correctas y normales, que se relacionan con su existencia como sujetos, en la medida en que se inserten a las redes de poder, que son las que les dan el verdadero sentido de existencia como sujetos. Por ejemplo, el siguiente cuadro hace referencia a lo mencionado anteriormente:

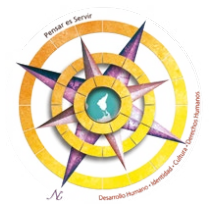


Cuadro 2. Contenidos sobre sexualidad en el Programa de Enseñanza de la Religión 2004

\begin{tabular}{|c|c|c|}
\hline Objetivo & Contenido & Actitudes \\
\hline $\begin{array}{l}\text { Analizar la vivencia } \\
\text { de la sexualidad } \\
\text { dentro de su proyecto } \\
\text { de vida como vivencia } \\
\text { cristiana de amor y de } \\
\text { compromiso social. }\end{array}$ & $\begin{array}{l}\text { Proyecto de vida } \\
\text { y la vivencia de la } \\
\text { sexualidad. } \\
\text { La sexualidad } \\
\text { manifestación de } \\
\text { amor y compromiso } \\
\text { social, según } \\
\text { principios cristianos. }\end{array}$ & $\begin{array}{l}\text { Interés por conocer } \\
\text { los planteamientos } \\
\text { cristianos. Adopción } \\
\text { de comportamientos de } \\
\text { honestidad en las relaciones } \\
\text { que se establece con } \\
\text { personas de diferente género } \\
\text { y edad. } \\
\text { Adopción de } \\
\text { comportamientos de } \\
\text { honestidad en las relaciones } \\
\text { que se establece con } \\
\text { personas diferente género y } \\
\text { edad. } \\
\text { Ejercitación de la equidad en } \\
\text { las relaciones cotidianas que } \\
\text { se establecen con personas } \\
\text { de igual o diferente sexo, } \\
\text { valores. }\end{array}$ \\
\hline
\end{tabular}

Nota: Tomado del Programa de Religión del MEP 2004.

En palabras de Foucault, el poder disciplinario crea los individuos (en relación con la norma) a través de rituales basados en una supuesta verdad que únicamente responde a intereses hegemónicos normalizadores (Díaz, 2013, p. 4). Sin embargo, es importante mencionar que los discursos no son entidades con voz propia, sino que son producidos por sujetos o personas, y proporcionan una ventaja en la medida en que los cambios generacionales van transformando las estructuras mentales, ideológicas y culturales; impactan las narrativas discursivas hegemónicas dentro de las estructuras legítimas, como puede ser el Ministerio de Educación Pública y otras esferas significativas de poder. Un ejemplo de ello se expresa en la siguiente nota periodística: 
Después de tres días de intensa discusión, la Asociación de Profesores de Segunda Enseñanza (APSE) fijó su posición en torno a la educación sexual que se imparte en los colegios públicos, en la cual no debe participar la Iglesia Católica, "por ser tan poco realista. Desde nuestra perspectiva, la Iglesia Católica no debe intervenir en la realización de nuevas guías sexuales de educación, pues es un tema muy delicado. Creemos que la Iglesia es poco realista, por lo que no puede colaborar con una propuesta científica, racional y real". (Arrieta Arias, 2004, p. 14)

En las esferas de poder también se producen transformaciones en el marco del espacio y tiempo, aquello que se defiende en un momento preciso y que representa un mecanismo disciplinario y de adiestramiento, con el paso del tiempo deja de tener el mismo impacto y eficiencia sobre los individuos. Esto explica porque algunos sectores (de acuerdo con la referencia anterior) tienen la posibilidad de desafiar estructuras de poder como la Iglesia Católica, dado que existe un contexto de reajuste de los cuerpos individuales y colectivos, producto de una mayor apropiación sobre sí mismos y un amplio cuestionamiento sobre las políticas de regulación. Alvarenga es muy acertada al referirse a que la apropiación de los cuerpos representa una amenaza a las políticas reguladoras y para quienes pretenden protegerlas.

La virulenta reacción de la opinión pública hegemónica en los años siguientes continuó lanzando sus dardos contra los comunistas presentándoles como promotores del caos sexual, acusación que podría afectar seriamente la relación con sus potenciales bases, predominantemente masculinas, de trabajadores urbanos y rurales, quienes no tenían ningún interés en promover una revolución centrada en el deseo que amenazaba su capacidad de controlar sexualmente a las mujeres. (Alvarenga, 2012, p. 112).

El contexto de la Costa Rica durante la primera década del siglo XXI no es nada alentador, el impulso hacia políticas morales y las discusiones ideológicas sobre qué se debe hablar sobre la sexualidad, para evitar un caos sexual, es una constante durante todo el periodo de estudio, pues los grupos conservadores, como la Iglesia y algunos sectores simpatizantes del conservadurismo, establecían que los programas estaban diseñados para promover el amor libre e irresponsable. Sin embargo, se estaba omitiendo una realidad innegable: el aumento de embarazos adolescentes y el contagio de infecciones de transmisión sexual, como

\section{La educación media como espacio de disputa La deconstrucción del discurso sobre la sexualidad en Costa Rica, 1960-2018 Hermes Campos-Monge}

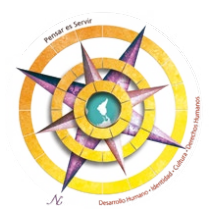


se puede constatar en la noticia publicada por la Prensa Libre:

Las cifras de adolescentes y niñas que esperan un hijo son alarmantes. En nuestro país existen aproximadamente 1500 niñas menores de 15 años embarazadas. Este índice alertó a la Defensoría de los Habitantes, que le solicito al Ministerio de Educación Pública (MEP) ahondar más en el tema de la educación sexual, dentro de los programas educativos. (Zúñiga Ureña, 2003, p. 5)

El Estado costarricense tenía consciencia de una realidad inevitable, las prácticas coitales en los adolescentes no podían detenerse, pero si era posible brindar una educación que le permitirá al sujeto tomar decisiones informadas $\mathrm{y}$ analizadas por ellos mismos. El discurso sobre la sexualidad tenía que cambiar, el Ministerio de Educación Pública omitía su responsabilidad en brindar una educación integral, es decir, considerando todas las variables sociales, culturales, ideológicas y económicas que implica la complejidad en su abordaje. Dado que existía la Política de Educación Integral de la Sexualidad Humana (MEP, 2001, p. 1), los resultados sobre la sociedad seguían limitados; no existía ningún programa sobre sexualidad, en el marco de esta política, para dar una respuesta o solución a los embarazos no planificados y a las infecciones de transmisión sexual.

Las últimas estadísticas de embarazo en el sistema educativo hablan de que el año pasado en secundaria estudian 1231 muchachas en estado de gestión. Esto significa que de cada mil estudiantes, 7,7 están embarazadas. Estos datos aunados a una encuesta elaborada por el programa Cuidarte es Quererte, farmacéutica alemana, reveló que de los 937 alumnos entrevistados en el Gran Área Metropolitana, $41 \%$ entre los 12 y 14 años y el $38 \%$ de los que tienen 15 años, reconocieron que ya iniciaron su vida sexual. Pero, más elementos se tornan preocupantes en esta situación, pues $31 \%$ de los que admitió tener una vida sexual no usa ningún método anticonceptivo, argumentando cosas como que "no lo había planeado", "fue inesperado" o "no lo tenía a mano en el momento”. (Zúñiga Ureña, 2003, p. 2).

Los programas oficiales y tradicionales del MEP, como ciencias, religión y educación para el hogar, solo reflejaban los flagelos que históricamente ha llevado a no concretar un programa cuyo contenido sobre sexualidad esté libre de investiduras morales. Esta tendencia, a través del tiempo, ha demostrado ser poco 
realista sobre las dinámicas y realidades de la sociedad. Bien lo menciona Bauman (2011), al referirse al concepto de baja colateral y a la invisibilidad de quien experimenta esas bajas colaterales, "Ambas categorías, aunque por razones diversas, se dejan fuera de consideración cada vez que se evalúan y calculan los costos de un emprendimiento y los riesgos que entrañan su puesta en acto" (p. 17). La lógica moralista no escatima su impacto sobre la realidad de los sujetos, porque lo que importa es la protección de los valores culturales y cristianos (como su objetivo primordial), aunque no necesariamente quienes están en espacios de toma de decisiones son los que experimentan los estragos de su propia política. Según Bauman (2011):

Las bajas se tildan de colaterales en la medida en que se descartan porque su escaza importancia no justifica los costos que implicarían su protección, o bien de inesperadas porque los planificadores no las consideran dignas de inclusión entre sus objetivos del reconocimiento preliminar. (p. 17)

Las distintas iniciativas del Estado por crear un programa que perdurara en el tiempo buscaban, en el sujeto, mayor autodeterminación y conocimiento de su propio cuerpo, mediante aspectos elementales como el derecho a la decisión informada, maternidades deseadas y programadas, así como la posibilidad de contar con un espacio legítimo dentro del sistema educativo que permitiera al estudiante plantear dudas, cambios o incertidumbres sobre sexualidad, sin que mediara el silencio y el tabú.

Es importante mencionar que el Ministerio de Educación como órgano legítimo y responsable en materia de educación es quien, oficialmente, tiene la potestad, la responsabilidad y la autoridad para desarrollar e implementar políticas y programas en materia de sexualidad. No obstante, de acuerdo con Cecilia Sevilla, "La UNESCO propone que una de las mejores formas en las que se les puede llegar a los estudiantes (jóvenes) es por medio de un programa, bien estructurado, con lecciones que se estén dando periódicamente a lo largo de un período también largo" (Sevilla y Campos, 2019). Es decir, que la forma para permear sobre la sexualidad requiere no solo los contenidos, sino una evaluación constante en un marco de tiempo, porque para cambiar e incidir en las estructuras sociales y culturales es necesario un diálogo permanente que visibilice todo aquello que la cultura quiere vetar sobre lo relacionado a este tema en particular.

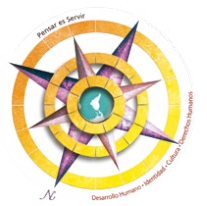


Desde la perspectiva de Foucault, es posible interpretar que los seres humanos han sido creados en un sistema cargado de dispositivos de control, incluida la educación. Sin embargo, resulta indispensable realizar una nueva lectura sobre esos mecanismos de control y considerar aquellos como la educación, que pueden volverse una herramienta de alto impacto en la transformación social. La educación tiene la particularidad de construir como también de deconstruir, porque los sujetos que reciben ese conocimiento no son seres lineales y receptivos, cada uno reconstruye su propio discurso sobre lo aprendido. Por lo tanto, la educación en sí misma es una plataforma con la capacidad de deconstruir, en la cual el discurso oficial puede cambiar en la medida que la educación sea un motor de aprendizaje mutuo, tanto para quienes la reciben como quienes la enseñan. En palabras Freire (1993):

Sin un mínimo de esperanza no podemos ni siquiera comenzar el embate, pero sin el embate la esperanza, como necesidad ontológica, se desordena, se tuerce y se convierte en desesperanza que a veces se alarga en trágica desesperación. De ahí que sea necesario educar la esperanza. Y es que tiene tanta importancia en nuestra existencia, individual y social, que no debemos experimentarla en forma errada, dejando que resbale hacia la desesperanza y la desesperación. (p. 25)

Aunque el argumento de Freire puede interpretarse como ingenuo, por la relevancia que le otorga a la esperanza, la educación debe mirarse como una alternativa posible para la transformación, no solo del discurso, sino social y cultural. Es necesario utilizar una institución legítima y avalada por el sistema, para promover, en los sujetos, un análisis serio de posibilidades, discusiones y experiencias donde las personas, desde su propia valoración, puedan concientizar sobre sus cuerpos, su sexualidad y donde las reglas privilegien la convivencia y no la opresión; porque como lo narra Freire (1993), "negar la libertad que tiene las personas de autoafirmarse, se corre el riesgo de exacerbar la autoridad" ( $p$. 39), es decir, la educación debe promover prácticas democráticas, donde se visibilice a quienes son vistos como extraños, porque amenazan el orden natural.

Desde el enfoque planteado por Freire, cuando se refiere a la educación como un espacio de deconstrucción, también es posible cuestionar las políticas reguladoras de cuerpo. Por ejemplo, en el 2012 se implementa 
el Programa Afectividad y Sexualidad Integral que reconoce la importancia de la autovaloración y el autoconocimiento sobre su sexualidad y corporalidad, como se explica en el siguiente texto:

Es esencial que cada persona disfrute del afecto, tanto de darlo como recibirlo, que desarrolle actitudes y prácticas que eviten discriminación ante las diferencias entre las personas o por género, que aprecie y practique la asertividad en la comunicación, el diálogo y la honestidad, que sepa conciliar las diferencias con sus pares y con las personas de otras edades, que pueda ser justa en relación con la participación de hombres y mujeres en la definición de sus necesidades y la toma de sus propias decisiones, que esté en capacidad de construir relaciones entre pares y de pareja en paz, armonía y disfrute. (MEP, 2012, p. 9)

Los canales oficiales desde donde se difunden los discursos (como los programas) pueden ser medios de deconstrucción, en la medida en que se posibilite el diálogo sobre la sexualidad, se visibilice la existencia de otros géneros humanos más allá del binarismo de género, donde las mujeres puedan elegir reproducirse o no, autoproclamándose dueñas de sus cuerpos sin que esto implique manifestaciones de violencia sexual y de dominio; donde las manifestaciones homoeróticas no signifiquen perversión ni sean motivo de exterminio y donde la identidad de género sea respetada; hasta que no llegue ese momento no se puede argüir que la esperanza tiene sentido en sí misma. Por ahora, la esperanza se entiende como sinónimo de lucha y resistencia constante frente a la educación no oficial como los simbolismos representados en los medios de comunicación, y en los mecanismos que emplea la cultura para proteger el orden natural, las familias y la política etc.

La educación sobre sexualidad en las primeras décadas de siglo XXI en el contexto costarricense responde a presiones generadas desde distintas voces de los sectores sociales, pero también de obligaciones que el Estado costarricense asume en los mecanismos proporcionados por el derecho internacional, como se expresa en la siguiente cita:

Cuando los programas se validan siempre van a sociedad civil, entonces cuando tenemos un borrador de programa, es este caso sobre todo por la temática que toca, eso va a sociedad civil; quiere decir que se consulta con expertos de las universidades, con organizaciones no gubernamentales

\section{La educación media como espacio de disputa \\ La deconstrucción del discurso sobre la sexualidad en Costa Rica, 1960-2018 Hermes Campos-Monge}

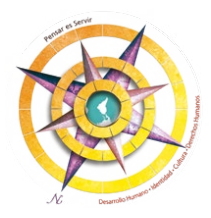


relacionadas con la temática, con PANIAMOR, PANI, Ministerio de Salud; toda la mayor cantidad de criterios que podamos tener y en ese caso ha involucrado a grupos religiosos, no solo la Iglesia Católica sino también grupos evangélicos e incluso la Casa Israelita. Ellos reciben el documento y hacen una devolución, donde hacen sus comentarios, donde hacen sus comentarios, que les parece, que no les parece, que le agregarían, que le quitarían. (Sevilla y Campos, 2019)

Tradicionalmente, referirse a discursos hegemónicos se asocia con la existencia de una institución que tiene la potestad de difundir y crear prácticas discursivas, las cuales responden a ciertas nociones propias de la cultura en un contexto determinado. No obstante, esos discursos son generados por sujetos, expuestos a situaciones relacionadas con los cambios generacionales, la visibilización de nuevos enfoques y perspectivas, y la transculturización (exposición y convivencia con otras culturas), que han comenzado a desplazar el dominio de los discursos hegemónicos, para abrirse a nuevas perspectivas y subjetividades propias de la dinámica de transformación social en el espacio-tiempo.
Las políticas y los programas creados desde el sistema educativo, además de ser instrumentos que determinan cómo se debe difundir el discurso sobre sexualidad, también se convierten en mecanismos de deconstrucción, porque son utilizados para cuestionar al mismo sistema, como ocurre con el Programa de Afectividad y Sexualidad Integral 2012. El cuestionamiento sobre las políticas de regulación de los cuerpos no es necesariamente exclusivo de sectores sociales externos, por lo menos durante las primeras décadas del siglo XXI, las disputas también se gestaban al interior del sistema por parte de los mismos sujetos que estaban involucrados en las Comisiones Curriculares, como se explica en la siguiente nota:

Yo fui parte activa junto con las otras personas que estábamos ahí, junto con este equipo que estaba en el CENADI. Muy probablemente por la situación administrativa, las estructuras de Gobierno obviamente, los Ministerios somos muy estructurados, como muy cuadrados; romper ese tipo de estructuras siempre trae sus crisis muy complejas y obviamente hay un costo particular, personal que se paga. Entonces en ese momento, había mucha plata de por medio, no plata ajena, plata tica, plata nacional, plata de que 
había que dar educación para la sexualidad, pero había que formar al personal docente y no había un Departamento, una Unidad Técnica Administrativa que asumiera, solo la gente del CENADI que eran 3 o 4 personas prestadas en función de esto y un carro que había prestado el (NCD) ${ }^{6}$ y todo ese cuento. (Arce, 2019)

Según el texto anterior, al referirse a los mecanismos oficiales de difusión como los programas y las políticas, también están sometidos a filtros o cuestionamientos por parte del personal, organizaciones no gubernamentales afines a la temática, Patronato Nacional de la Infancia, La Casa Israelita, Conferencia Episcopal, sociedad civil, Ministerio de Salud y expertos de las universidades, entre otras instituciones y organizaciones que participan de este proceso. Todos tienen claro que sus opiniones o sugerencias están sujetas al criterio técnico de la comisión del MEP, como lo indica Campos y Sevilla (2019):

Ellos reciben el documento y hacen una devolución, donde hacen sus comentarios, donde hacen sus comentarios, ¿Qué les parece? ¿Qué no les parece? ¿Qué le agregarían? ¿Qué le quitarían? etc. Y

6 NCD no se comprende el mensaje por la dicción del hablante recogida en la grabación la Comisión valora a lo interno que asumen y que no asumen de esas aportaciones. Entonces el papel que ha jugado la Iglesia es ese, dar su opinión, su criterio. Claramente hay algunos criterios que la Iglesia tiene que subyacen en las creencias religiosas que nosotros respetamos profundamente pero que se contraponen con lo que nosotros conocemos como una educación en sexualidad que sea verídica y científica para los chicos y chicas.

De acuerdo con lo anterior, existe una importante participación de distintos sectores sociales que tienen la posibilidad de sumar criterios para construir el programa sobre sexualidad. Sin embargo, existen sectores como los religiosos, a quienes se les limita la posibilidad de intervención, porque dentro del juego político del poder, aquellos sujetos sociales cuyos criterios no se comparten son eliminados del campo de juego.

Las personas que integran las comisiones tienen la posibilidad de objetar las posibles discrepancias técnicas y de contenido que pueden suscitar en los programas. No obstante, a pesar de existir un proceso democrático de consulta, el Estado deja claro que las disposiciones generadas no son de acatamiento obligatorio, lo cual margina estas voces

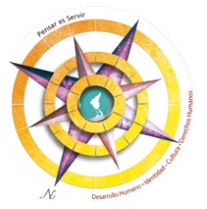


de la sociedad de una real participación. Esto permite que las ideologías tendenciosas que buscan homogenizar las corporalidades se distancien de la cientificidad con la que debe abordarse este tópico. De acuerdo con el Programa de Educación para la Afectividad y Sexualidad Integral se pueden identificar los siguientes contenidos:

Figura 1. Ejes temáticos abordados por el programa de Afectividad y Sexualidad Integral 2012

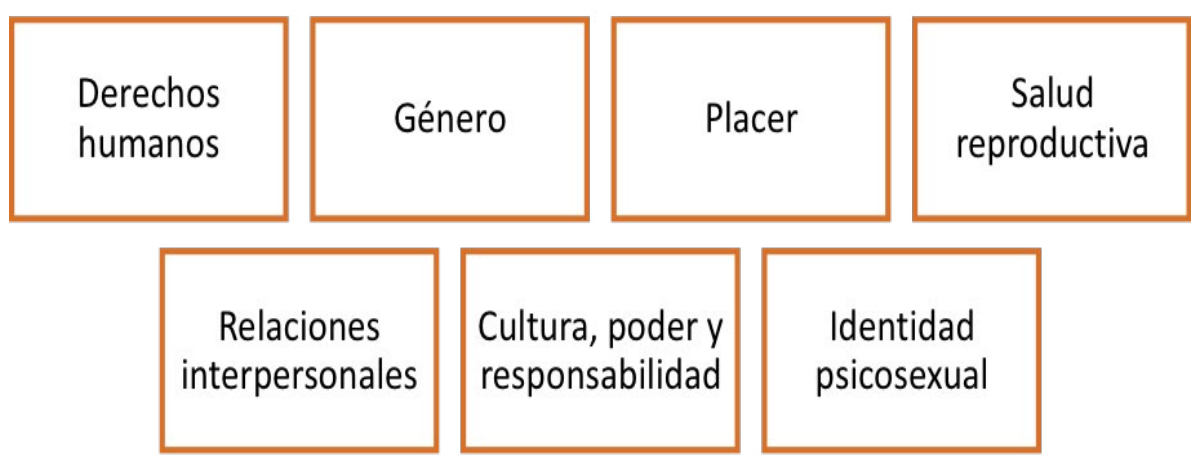

Nota: Elaboración propia a partir de información disponible en el Programa de Afectividad y Sexualidad Integral 2012 (incluido en el programa de ciencias 2012).

El programa es un instrumento general en el cual se plasma un discurso sobre la sexualidad emitido desde el Ministerio de Educación Pública, pero para sostener ese discurso es necesario que la entidad legítima (MEP) pueda encontrar apoyo en distintos sectores estratégicos como puede ser la familia o la comunidad y el mismo personal docente, quien imparte las clases. Sin embargo, como lo establece Miliband (1984, citando a Skocpol), "el Estado es una característica de todos los modos de producción divididos en clase, donde la única función necesaria e inevitable del Estado (por definición) es contener los conflictos de clase y adoptar otras medidas en defensa de la dominación de clase" (pp. 
124-125). Desde esta lógica, el Estado no es una estructura totalmente autónoma, porque aunque tiene intereses propios, estos están sujetos a los de las personas que lo dirigen. Un ejemplo que evidencia el poder y la discursividad es el siguiente:

Costa Rica no quiere más ideología de género ni utilización de recursos públicos en temas que no son prioritarios en nuestros centros educativos. Los estudiantes de secundaria se encuentran en huelga desde el lunes anterior pidiendo la salida del ministro Mora, además se manifiestan en contra de algunas medidas tomadas por el Ministerio de Educación (MEP) como los baños neutros y la compra de drones, las pruebas de Fortalecimiento de Aprendizajes para la Renovación de Oportunidades (FARO) y el proyecto de Educación Dual. (Angulo 2019)

Aunque la noticia esta fuera del periodo analizado, es necesario mostrarla como una prueba del poder en el juego político. El Estado costarricense intenta responder a las crispaciones de la sociedad sobre temas polémicos y desafiantes de la cultura heteronormativa preexistente, donde su función "es contener los conflictos de clase y adoptar otras medidas en defensa de la dominación de clase" (Miliband, 1984, p. 125). Sin embargo, cabe la posibilidad de que el Estado también puede llegar a tener "desavenencias con los intereses entre la clase o el conjunto de grupos dominantes" (Miliband, 1984, p. 125) y, por otro lado, con los dirigentes del Estado, como se evidencia en la noticia. Además, los intereses coyunturales que pueda tener el Estado, en determinado contexto histórico, puede encontrar aliados, quienes se identifican con sus políticas y, eventualmente, como lo indica Campos y Sevilla (2019):

Con los de ciencias ya se rompió un poco con el primer programa. Es que vieras las capacitaciones entre ciencias... Gracias que las autoridades pensaron que había que ponerle a alguien a los de ciencias. Ciencias, aquella rigurosidad sentados cuestionando todo y los de orientación, aquella camaradería. Y sirvió un montón para romper esa cosa.

El discurso sobre la sexualidad está inscrito en un campo de poder en diferentes niveles, en los cuales puede encontrar desavenencias o intereses comunes; de ahí la importancia de que el docente pueda reconocer elementos que le permitan abordar el tópico sin que este deba ser antagónico. No obstante, las transgresiones siempre van a generar rechazo y escepticismo, ya sea por desconocimiento e

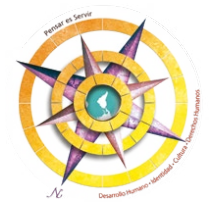


ignorancia o por estereotipos o ideas preconcebidas originadas desde el imaginario colectivo. Por lo tanto, tratándose de un programa de sexualidad como el PASI, construido desde fuera del espacio familiar, genera incertidumbre, porque es a la familia a quien se le atribuye esta función por antonomasia.

El PASI (Programa de Afectividad y Sexualidad Integral) ha sido una obligación pendiente del Estado costarricense y un esfuerzo necesario para transgredir las nociones tradicionales que han revestido este tema. Además de representar un mecanismo difusor oficial -aunque puede presumirse de un discurso hegemónico-, también representa un espacio de cuestionamiento a las políticas tradicionales gestadas por el Ministerio de Educación.

Los discursos hegemónicos se asocian a estructuras conservadoras cuyas narrativas buscan la pérdida absoluta del control de los cuerpos, así como su expropiación mediante dispositivos de control como son las políticas y programas. Esta es la forma en la que funciona el bio-poder, mediante la apropiación de las cotidianidades como una "maquina o dispositivo disciplinario que opera sobre los cuerpos para volverlos dóciles" (Toscano López, 2008, p. 47).
No obstante, aunque la educación pueda estar permeada de dispositivos de control, es necesario valorar la posibilidad de utilizarla como un mecanismo de deconstrucción y de cuestionamiento del orden natural donde, en palabras de Paulo Freire, es posible utilizar técnicas pedagógicas que posibiliten a los sujetos (estudiantes) desafiar por medio de la crítica y la reflexión, discursos dominantes prevalecientes en la cultura y en la sociedad. Por lo tanto, es necesario evaluar los mecanismos de difusión oficiales como mecanismos autocríticos en la medida en que existan nuevos actores, con novedosas perspectivas, alejadas de tradicionalismos, como ha ocurrido con el PASI; un programa que rompe con la idea de una sexualidad centrada en la genitalidad, la biología y la fisiología.

\section{Conclusiones}

La sexualidad es un espacio de disputa por el control y subordinación de los cuerpos, pero al mismo tiempo, es un poder que depende de la voluntad y la docilidad para ser objeto de ese poder, pues la resistencia es una alternativa que desestabiliza un sistema perverso que intenta mantener el orden hegemónico.

La necesidad de dominar las conductas cotidianas se ha convertido 
en instrumento de discusión política, una verdadera invasión a la privacidad y un asalto a la democracia, porque la posibilidad de ser está limitada a los controles institucionales y culturales, que regulan y establecen, mediante códigos de normalidad y normativismo, la forma en la que deben comportarse hombres y mujeres.

La construcción y legitimación del discurso de la sexualidad en Costa Rica no está limitado a la versión oficial del Estado, existen muchos lugares y sectores sociales desde donde se emiten discursos, se construye y deconstruye la narrativa de la sexualidad. Por lo tanto, es una narrativa vrs discurso, en tanto exista participación de distintos actores y escenarios; pese a que la legitimidad oficial sobre la enseñanza de la sexualidad recae en el MEP, la existencia de otras voces no oficiales siempre estarán en escena, porque son las que promueven las posibilidades de apertura de los discursos oficiales, para incorporar sus visiones.

La educación media no solo es un espacio de disputa, es una representación de las distintas narrativas, pues los sujetos no solo interactúan con el sistema educativo, también lo hacen con las construcciones simbólicas sobre la sexualidad que existen en la sociedad, en los medios de comunicación, en las familias, en los lugares de recreación, centros de pensamiento etc., lugares desde donde se generan transformaciones y resistencias para mantener el "status quo" o para desafiar las normativas culturales y sociales sobre la sexualidad.

No obstante, aunque la educación pueda estar permeada de dispositivos de control, es necesario valorar la posibilidad de utilizarla como un mecanismo de deconstrucción y de cuestionamiento del orden natural donde, en palabras de Paulo Freire, es posible utilizar técnicas pedagógicas que posibiliten, en los sujetos (estudiantes), desafiar por medio de la crítica y la reflexión, discursos dominantes prevalecientes en la cultura y en la sociedad. Por lo tanto, es necesario revalorar los mecanismos de difusión oficiales como mecanismos autocríticos, en la medida en que posibiliten la deconstrucción de esos discurso hegemónicos, con novedosas perspectivas, alejadas de tradicionalismos, como ha ocurrido con el PASI (Programa de Educación para la Sexualidad y Afectividad Integral), un programa que rompe con la idea de una sexualidad centrada en la genitalidad, la biología y la fisiología.

\section{La educación media como espacio de disputa La deconstrucción del discurso sobre la sexualidad en Costa Rica, 1960-2018 Hermes Campos-Monge}

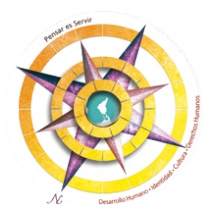




\section{Referencias}

Alvarenga, P. (2012). Identidades en disputa: Las reivindicaciones del género y de la sexualidad en la Costa Rica de la primera mitad del siglo XX. Editorial UCR.

Amigot Leache, P. y Pujal i Lombart, M. (2009). Una lectura del género como dispositivo de poder. Revista Sociológica, p. $70 \mathrm{http}: / / \mathrm{www}$. sociologicamexico.azc.uam.mx/index.php/ Sociologica/article/view/145/136

Angulo, Y. (01 de junio 2019). "No queremos otro activista como Ministro de Educación, señala Nueva República". Elmundo. https://www.elmundo. cr/costa-rica/no-queremos-otro-activista-como-ministro-de-educacion-senala-nueva-republica/

Arrieta Arias, E. (14 de agosto 2004). Iglesia no debe intervenir en educación sexual. faltan datos, p.7.

Arroyo Navarrete, L. (2008). El derecho a la educación integral para la sexualidad y las y los adolescentes en Costa Rica desde la perspectiva de género [Tesis de licenciatura]. Universidad de Costa Rica. http://iij.ucr.ac.cr/wp-content/ uploads/bsk-pdf-manager/2017/07/ E1-Derecho-a-la-Educaci \% C3\% B3n-Integral-para-la-Sexualidad-de-las-y-los-Adolescentes-en-Costa-Rica-desde-la-Perspectiva-de-G\%C3\%A9nero..pdf

Avendaño, C. (22 de diciembre, 2003). Educación sexual integral: una urgente necesidad, El Heraldo de la Nueva Era, p.14.
Báez, L. (2001). Gobierno aprueba política de educación de la sexualidad, $\mathrm{El} \mathrm{He}$ raldo, p. 32 .

Bauman, Z. (2011). Daños colaterales: desigualdades en la era global. Editorial Impresora y Encuadernadora Progreso.

Bloch, Vital, H. (julio-diciembre 2013). Betty Friedan: El trabajo de las mujeres, el liberalismo posterior a la Segunda Guerra Mundial y los orígenes del liberalismo femenil en Estados Unidos. Revista Signos Históricos, 30. http://www.redalyc.org/ pdf/344/34428955003.pdf

Bottticelli, S. (agosto-octubre 2015). La gubernamentalidad del Estado en Foucault: Un problema moderno. Revista Praxis Filosófica, 42.

Bourdieu, P. (2000). La dominación masculina. Editorial ANARGRAMA.

Brenes Camacho, G. (2014). Describiendo procesos históricos de "baby boom" durante mediados del siglo XX en tres nacionales latinoamericanas usando estudios de envejecimiento. En Propuesta de trabajo en el VI Congreso de la Asociación Latinoamericana de Población. Centro Centroamericano de Población y Escuela de Estadística, Universidad de Costa Rica. http://www.alapop.org/ Congreso2014/DOCSFINAIS_PDF/ ALAP_2014_FINAL96.pdf

Cantero, M. (29 de octubre 1999). Educación sexual sin dar frutos. La República, $7^{\mathrm{a}}$. 
Cartín, T. (2019). Breve cronología de la educación de la sexualidad en Costa Rica. MEP.

Castillo, J. P. (8 de abril 2001). Comienza la distribución de guía sexual. Eco Católico, p. 10.

Castro, E. (julio 2016). La verdad del poder y el poder de la verdad en los discursos de Michael Foucault. Revista Tópicos, 31 .

Centro Feminista de Información y Acción. (s. f.). Sobre CEFEMINA. https:// www.cefemina.com/Nueva/

Chacón Román, M. (26 de octubre 1999). Acuerdo sobre la educación sexual. Al Día, p. 3.

Conde Soto, F. (marzo-octubre 2017). El cuerpo más allá del organismo: el estatus del cuerpo en el psicoanálisis lacaniano. Revista Internacional de Filosofía Contrastes, 2.

Conferencia Episcopal de Costa Rica. (2001). Educación en la sexualidad: Guía para padres de familia y educadores. CONEC.

Díaz, M. (mayo-septiembre 2013). Del disciplinamiento de los cuerpos al gerenciamiento de la vida. Mutaciones biopolíticas en el presente en torno a la construcción de la anormalidad. Revista de Prácticas y Discursos, 2. http://biblioteca.clacso.edu.ar/Argentina/ces-unne/20141001053149/ Diaz.pdf

Eco Católico. (09 de agosto 1992). Guías de Sexualidad Humana. Eco 2.

Eco Católico. (16 de agosto 1992) Carta de presentación al señor Ministro de Educación, de la respuesta de la Conferencia Episcopal a la consulta sobre las Guías Didácticas de Sexualidad. Eco 2.

Facio, A. y Fries, L. (2005). Feminismo, género y patriarcado. Revista sobre Enseñanza del Derecho de Buenos Aires, 3(6). http://www.derecho. uba.ar/publicaciones/rev_academia/ revistas/06/feminismo-genero-y-patriarcado.pdf

Fausto-Sterling, A. (2006). Cuerpos sexuados: La política de género y la construcción de la sexualidad. Melusina.

Foucault, M. (2003). Disciplina: Los cuerpos dóciles. En Vigilar y Castigar Nacimiento de la Prisión. Siglo Veintiuno Ediciones Argentina.

Freire, P. (1993). Pedagogía de la esperanza: Un reencuentro con la pedagogía del oprimido. Editorial Siglo XXI. http://enlaceacademico.ucr.ac.cr/ sites/default/files/publicaciones/PEDAGOG\%C3\%8DA\%20DE\% 20 LA\%20ESPERANZA-FREIRE.pdf

La Nación. (17 de marzo 1974). Educación sexual basada en una concepción materialista, p. 8 .

La Nación. (19 de agosto 1971). Inaugurando seminario de educación sexual para auxiliares de orientación, p. 47.

La Nación. (20 de marzo 1974). Educación sexual: limpia su trayectoria y cristianos todos sus fundamentos, p. 32 .

Lorite Mena, J. (1995). Sociedades sin Estado. El pensamiento de los otros. Ediciones Akal. 
Malavassi, G. (28 de febrero 1979). El problema sexual, La Nación, p. 15.

Miliband, R. (enero-marzo 1984). Poder estatal e intereses de clase. Revista Zona Abierta, 30.

Ministerio de Educación Pública.(1964).Memoria Anual 1963. MEP. https://mep. janium.net/janium-bin/pdfview.pl?I$\mathrm{d}=20200429124249 \& \mathrm{r}=170804 \&$ $\mathrm{t}=\mathrm{p}$

Ministerio de Educación Pública. (1985). Guía Didáctica en Sexualidad y Vida Familiar $9^{\circ}$ Tercer Ciclo. FNUAP-MEP-UNESCO.

Ministerio de Educación Pública. (2001). Política de Educación Integral de la Expresión de la Sexualidad Humana.

Ministerio de Educación Pública. (1965). Programa de Educación para el Hogar, Tercer Ciclo. MEP.

Ministerio de Educación Pública. (1979). Programa de Ciencias Generales, Tercer Ciclo. MEP.

Ministerio de Educación Pública. (1985). Proyecto Educación en Población -Costa Rica-: Guía didáctica de sexualidad humana y vida familiar $7^{\circ}$. Imprenta Nacional.

Ministerio de Educación Pública. (1989). Proyecto de Educación en Población -Costa Rica- Guía didáctica de Sexualidad Humana y Vida Familiar $7^{\circ}$ Tercer Ciclo. FNUAP-MEP-UNESCO

Ministerio de Educación Pública. (1990). Programa de Educación para el Hogar Tercer Ciclo. Imprenta Nacional.
Ministerio de Educación Pública.(1993) Proyecto Educación en Población-Costa Rica- Guía Didáctica de Sexualidad Humana $9^{\circ}$. MEP-UNESCO.

Ministerio de Educación Pública. (1999) Manual didáctico de sexualidad humana $8^{\circ}$ Tercer Ciclo. MEP.

Ministerio de Educación Pública. (2012). Programa de Enseñanza de las Ciencias: Programa de Afectividad y Sexualidad Integral Tercer Ciclo. MEP.

Molina Jiménez, I. (2019). Deliciosas tempestades. Las mujeres y la educación sexual en Costa Rica entre 1920 y 1960. Revista Descentrada, 3(1). http://www.memoria.fahce.unlp.edu. ar/art_revistas/pr.9641/pr.9641.pdf

Monestel Arce, Y. (10 de mayo de 1960). La educación sexual y el Estado, $L a$ Prensa Libre, p. 2.

Mora, E. (6 de septiembre 1999). Obispos cuestionan los programas sexuales. La Nación, p. 16.

Oficina de la Primera Dama, Consejo Interinstitucional de Atención a la Madre Adolescente, Instituto Nacional de las Mujeres. (1999). Amor Joven y Construyendo Oportunidades. Imprenta Nacional.

Osorio, J. (2012). Estado, biopoder y exclusión: Análisis de la lógica del capital. Editorial Anthropos.

Picado Gatjens, M. (2006). Sexualidad y catolicismo. Editorial Lara Segura.

Poder Judicial de Costa Rica, Sala Constitucional: sentencia 16583-15 
Preciado, B. (2002). Manifiesto contrasexual: Prácticas subversivas de identidad sexual. Editorial Opera Prima.

Programas, documentos oficiales del MEP y otras instituciones.

Ranucci. (30 de mayo 1959). Educación sexual y coeducación, La República, p. 20.

Sáenz Valverde, G. (29 de agosto 2000). A los adolescentes hay que hablarles claro sobre sexo. Diario Extra, p. 6.

Sánchez Amaya, T. (2013). La evaluación educativa como dispositivo de constitución de sujetos. Revista Latinoamericana de Ciencias Sociales, Niñez y Juventud, 11(2), p. 756. http:// www.scielo.org.co/pdf/rlcs/v11n2/ v11n2a21.pdf

Schifter Sikora, J. (1989). La formación de una contracultura: Homosexualismo y SIDA en Costa Rica. Ediciones Guayacán.

Toscano López, D. (2008). El bio-poder en Michael Foucault. Revista Universitas Philosophica, 25(51).

Valerio Charpentier, E. (1993). Marina Peralta Villalobos, Guía Didáctica de Educación en Población $7^{\circ}$ Tercer Ciclo. MEP-UNESCO.

van Dijk, T. A. (septiembre-octubre 1999). El análisis crítico del discurso. Revista Anthropos. http://www.discursos.org/oldarticles/E1\%20an\%E1lisis $\% 20$ cr $\%$ EDtico $\% 20$ de $1 \% 20$ discurso.pdf

Vio Hernández, F. (14 de diciembre 2000). La Iglesia desaprobó los programas
"Amor Joven" y "Construyendo Oportunidades”. La Prensa Libre, p. 12

Wittig, M. (2006). El pensamiento heterosexual y otros ensayos. Editorial EGALES.

Zúñiga Ureña, L. (23 de octubre 2003) Defensoría externó su preocupación por el índice de embarazos en adolescentes. La Prensa Libre, p. 5.

Zúñiga Ureña, L. (23 de octubre 2003). Programas educativos deberán ahondar en educación sexual. La Prensa $\mathrm{Li}_{\text {- }}$ bre, p. 5.

Zúñiga Ureña, L. (23 de octubre 2003). Reconocen vacío en materia de sexualidad. La Prensa Libre, p. 2. 